\title{
Dukungan Komunitas Belajar dan Ketekunan Akademik Pada Mahasiswa Titin Suprihatin ${ }^{1}$, Erni Agustina Setiowati ${ }^{2}$
}

\author{
${ }^{1,2}$ Fakultas Psikologi Universitas Islam Sultan Agung, Semarang, Indonesia \\ titin@unissula.ac.id
}

\begin{abstract}
Abstrak
Ketekunan akademik sangat diperlukan bagi mahasiswa agar dapat menyelesaikan pendidikan di perguruan tingggi dengan baik. Tujuan penelitian ini untuk mengetahui korelasi dukungan komunitas belajar terhadap ketekunan akademik pada mahasiswa. Responden dalam penelitian ini adalah mahasiswa fakultas psikologi universitas $\mathrm{X}$ berjumlah $(\mathrm{n})=214$ yang terdiri dari 47 laki-laki dan 167 perempuan, dengan teknik sampling menggunakan cluster random sampling. Pengumpulan data menggunakan skala dukungan sosial dengan realiabilitas alpha cronbach 0,957 dan skala ketekunan akademik dengan reliabilitas alpha cronbach 0,865 . Hasil analisa data menggunakan uji korelasi product moment pearson diperoleh koefisien korelasi $\mathrm{r}_{\mathrm{xy}}=0,565$ dengan signifikansi $(p)=0,000(p<0,001)$. Hasil ini membuktikan bahwa dukungan sosial komunitas belajar berkorelasi positif dengan ketekunan akademik. Implikasi dari penelitian ini bahwa mahasiswa perlu memiliki kelompok belajar yang dapat memberi dukungan secara akademik maupun non akademik.
\end{abstract}

Kata Kunci: ketekunan akademik; dukungan sosial; prestasi akademik

\begin{abstract}
Academic persistence was very necessary for students to be able to complete their education in college well. The purpose of this study was to determine the correlation between learning community support and academic persistence in students. Respondents in this study were students of the psychology faculty of the University of X totaling $(\mathrm{n})=214$ consisting of 47 men and 167 women, with a sampling technique using cluster random sampling. Data collection uses a social support scale with Cronbach's alpha reliability $=0.957$ and academic persistence scale with Cronbach's alpha reliability $=0.865$. The results of data analysis using the Pearson product moment correlation test obtained a correlation coefficient of $r_{x y}=0.565$ with a significance $(p)=0.000(p<0.001)$. These results prove that the social support of the learning community was positively correlated with academic persistence. The implication of this research is that students need to have study groups that can provide academic and non-academic support.
\end{abstract}

Keywords: academic persistence; social support; academic achievement

\section{PENDAHULUAN}

Transisi menuju jenjang pendidikan yang lebih tinggi merupakan situasi yang penuh tekanan pada mahasiswa (Skahill, 2002). Terdapat banyak persoalan yang dihadapi mahasiswa selama masa studinya di perguruan tinggi meliputi masalah keuangan, latarbelakang keluarga dan pekerjaan, hubungan personal, masalah rumah tangga dan keluarga, penyesuaian terhadap tugas kuliah, serta masalah masa depan dan pekerjaan (Yahya \& Bahri, 2016).

Menurut Skahill (2002) mahasiswa baru di perguruan tinggi harus beradaptasi dengan sistem baru, kelas baru, dan lingkungan baru. Mahasiswa harus menyesuaikan diri dengan sistem pendidikan baru; mahasiswa harus memahami proses administrasi dan berbagai layanan yang disediakan oleh kampus dan sebagainya. Dengan berbagai persoalan ini, mahasiswa perlu mengembangkan keterampilan koping yang membantu mereka menghadapi tantangan di perguruan tinggi dan kehidupan sebagai mahasiswa, terlebih pada mahasiswa yang untuk pertama kalinya meninggalkan keluarganya demi melanjutkan studi. Ketekunan sangat diperlukan agar mahasiswa dapat menyelesaikan pendidikan di perguruan tingggi dengan baik. Ketidakmampuan untuk menangani tuntutan-tuntutan ini, akan berdampak terhadap studi 
mahasiswa yang memungkinkan terjadinya drop out atau putus studi. Penelitian Siddiq dkk menunjukkan bahwa jejaring sosial, termasuk keluarga dan teman sebaya, penting bagi siswa selama masa transisi mereka dari sekolah menengah ke pendidikan tinggi (Shiddiq et al., 2020)

Mahasiswa tahun pertama fakultas psikologi universitas x juga mengalami fenomena sebagai mahasiswa baru dengan berbagai tuntutan akademik dan non akademik. Ketidakmampuan menyesuaikan diri dengan berbagai tuntutan tersebut menyebabkan angka non aktif mengalami peningkatan, sebagaimana data yang penulis peroleh dari bagian administrasi akademik, bahwa pada tahun akademik 2020/2021 terdapat mahasiswa yang tidak aktif sebanyak 19\% dari mahasiswa angkatan 2018, 12\% dari mahasiswa angkatan 2019 dan 10\% dari mahasiswa angkatan 2020 (Bagian Administrasi Akademik (BAA), 2021)

Ketekunan akademik menurut (Roland et al., 2016) merupakan suatu komitmen untuk belajar. Individu yang tekun akan mengarahkan perilakunya pada tindakan menuju kepada tujuan pendidikan (misalnya mendapatkan gelar sarjana). Ketekunan adalah proses yang berlangsung terus menerus, selama mahasiswa menjalami perkuliahan sepanjang tahun, dengan menunjukkan berbagai perilaku yang mengarah kepada tujuan (misalnya, menghadiri kuliah dan praktik, waktu yang dihabiskan untuk belajar selama seminggu atau selama akhir pekan). Ketekunan diwujudkan dalam bertahannya mahasiswa dalam bidang studi yang sama. Ketekunan adalah sifat penting yang perlu dimiliki oleh mahasiswa. Ketekunan berarti menolak untuk menyerah dan terus berusaha mengejar tujuan meskipun menghadapi kesulitan. Hal ini melibatkan kemampuan untuk melihat kegagalan sebagai pengalaman belajar yang positif dan terus mencoba hingga tujuan pembelajaran tercapai.

Berbagai faktor diidentifikasikan dapat mempengaruhi ketekunan akademik, diantaranya adalah faktor latar belakang yang meliputi etnis, penghasilan orang tua, tingkat pendidikan orang tua, jenis kelamin, pendidikan subjek, serta faktor motivasi (misalnya nilai harapan, niat, kemampuan diri (Roland et al., 2016). Penelitian Lotkowski et al., (2004), membuktikan faktor yang ikut mempengaruhi ketekunan akademik mahasiswa saat di perguruan tinggi adalah status sosial ekonomi, prestasi akademik saat sekolah menengah, komitmen, tujuan akademik, dukungan sosial, efikasi diri akademik, dan keterlibatan sosial (Lotkowski et al., 2004). Selain itu nilai tugas yang diperoleh dan harapan akademis secara signifikan memprediksi ketekunan siswa (Muwonge et al., 2017).

Kehadiran dukungan sosial di dalam maupun di luar aktivitas akademik membantu mahasiswa untuk bergerak maju. Salah satu kontribusi utama dukungan adalah untuk memberikan siswa kepercayaan diri dan kemampuan mereka untuk berhasil dan bertahan menjalani studi (Roland et al., 2016). Penelitian terdahulu menggarisbawahi pentingnya dukungan sosial dalam mengimbangi kurangnya minat, kurangnya kepercayaan, dan kurangnya integrasi sosial. Ini memperkuat gagasan bahwa manusia adalah makhluk dimana kehadiran orang lain dapat mengatasi serangkaian kesulitan (Roland et al., 2016). Dukungan sosial berhubungan negatif dengan kesepian dan berhubungan positif dengan ketekunan akademik. Rendahnya rasa kesepian dan lebih banyak dukungan sosial memprediksi ketekunan yang lebih positif (Nicpon et al., 2006).

Mengingat, bahwa mahasiswa yang dapat menyelesaikan studi di universitas memiliki peluang yang lebih baik dalam hal mendapatkan pekerjaan yang lebih baik dimasa yang akan datang, sangat penting untuk mengetahui faktor yang berkorelasi dengan ketekunan mahasiswa dalam menyelesaikan pendidikan yang ingin dicapai. Beberapa hasil penelitian yang penulis paparkan di atas menunjukkan bahwa faktor dukungan sosial berpengaruh terhadap ketekunan mahasiswa. Penelitian-penelitian tersebut dilakukan dalam budaya dan 
konteks yang berbeda dengan penelitian yang penulis lakukan. Berdasar latar belakang di atas, penulis menilai penting untuk menguji apakah dukungan sosial teman atau komunitas belajar berpengaruh terhadap ketekunan akademik mahasiswa fakultas psikologi universitas $\mathrm{x}$.

\section{METODE}

Populasi penelitian adalah mahasiswa fakultas psikologi universitas x. Sample penelitian adalah mahasiswa semester satu dan tiga yang berjumlah 214, dengan rincian jenis kelamin laki-laki 47 orang dan perempuan 167 orang. Penentuan subjek berdasarkan teknik cluster random sampling. Berdasarkan semester yang sedang ditempuh oleh subjek, diperoleh subjek semester tiga 103 dan subjek yang berada di semester lima sebanyak 111.

Untuk mengukur ketekunan akademik digunakan skala ketekunan yang disusun oleh (Thalib et al., 2018) yang terdiri dari aspek mengejar tujuan jangka panjang (long-term purposes pursuing), mengejar tujuan saat ini (current purposes pursuing) dan mengulang tujuan yang tidak tercapai (recurrence of unattained purposes). Skala terdiri dari 45 aitem dengan koefisien reliabilitas alpha cronbach 0,816.

Skala dukungan komunitas belajar disusun berdasarkan skala dukungan sosial yang disusun berdasarkan bentuk-bentuk dukungan sosial dari Sarafino dan Smith (2014) mencakup dukungan emosional, dukungan penghargaan, dukungan berwujud atau instrumental, dukungan informasi, dan dukungan jaringan sosial atau persahabatan. Skala terdiri dari 40 item dengan koefisien reliabilitas alpha 0,957 .

\section{HASIL}

Hasil uji normalitas data menunjukkan nilai KS-Z $=0,673$ dengan $\mathrm{p}=0,756(\mathrm{p}>0,001)$ pada variabel dukungan komunitas belajar dan $K S-Z=0,902$ dengan $p=0,390(p>0,001)$ pada variable ketekunan akademik. Hasil ini menunjukkan bahwa data masing-masing variabel terdistribusi secara normal. Hasil uji linieritas variabel dukungan komunitas belajar dan ketekunan akademik diperoleh koefisien linieritas $\mathrm{F}=53,025(\mathrm{p}<0,000)$, menunjukkan bahwa hubungan antara dukungan komunitas belajar dan ketekunan akademik membentuk garis linier. Hasil pengujian hipotesis dengan menggunakan teknik analisis korelasi product moment diperoleh koefisien korelasi $\left(\mathrm{r}_{\mathrm{xy}}\right)=0,565$ dengan $\mathrm{p}=0,000$ yang berarti terdapat hubungan positif antara dukungan komunitas belajar dengan ketekunan akademik.

Berdasarkan hasil analisis deskriptif, diperoleh rata-rata (mean) data ketekunan akademik adalah 142,27 dengan standar deviasi $(\mathrm{SD})=14,00$, skor minimum 102 dan maksimum 188 . Untuk variabel dukungan kelompok belajar didapat skor rata-rata (mean) adalah 157,51 dengan standar deviasi 20,44, skor minimum 71 dan maksimum 199.

\section{DISKUSI}

Hasil penelitian ini membuktikan bahwa dukungan komunitas belajar berkorelasi positif dengan ketekunan akademik pada mahasiswa. Hasil penelitian ini sejalan dengan penelitian terdahulu bahwa variabel dukungan sosial adalah prediktor terkuat dari ketekunan akademik (Gloria \& Ho, 2003), dukungan sosial berkontribusi terhadap kesuksesan mahasiswa (Baker, 2017), dan menurut Rolland (2016) terdapat empat penentu dari ketekunan akademik, yakni minat, kepercayaan diri (self-efficacy), integrasi sosial dan dukungan sosial.

Hasil yang diperoleh pada penelitian ini dapat dimaknai bahwa kuatnya korelasi antara dukungan sosial kelompok belajar dengan ketekunan akademik $\left(\mathrm{r}_{\mathrm{xy}}=0,565\right)$ karena mahasiswa merasa telah mendapat dukungan dari orang-orang di sekitarnya sehingga memiliki dorongan 
kuat untuk terlibat dalam berbagai kegiatan akademik maupun non akademik. Hal ini juga tampak dalam aktivitas perkuliahan dimana mahasiswa sangat antusias dengan kegiatan belajar yang melibatkan kelompok, pembuatan tugas kelompok dan proyek independent kelompok.

Dukungan sosial dapat dipahami secara luas sebagai penyediaan sumber daya psikologis dan material dengan maksud membantu penerima dukungan untuk mengatasi stress (Cohen, 2004). Adanya perasaan didukung dan diterima memiliki fungsi energi, yang membangkitkan antusiasme, minat dan kemauan untuk berpartisipasi dan terlibat dalam kegiatan akademik (Cohen, 2004; Furrer \& Skinner, 2003). Selain itu, dampak dari keterlibatan secara sosial pada mahasiswa lebih kepada penurunan tingkat stres yang terbentuk oleh adanya ikatan sosial (Grant et al., 2009). Dukungan pertemanan secara positif berkorelasi dengan kepuasan dan ketekunan di perguruan tinggi dan bahwa memiliki teman dengan pola pikir akademik yang sama bermanfaat bagi keberhasilan akademik (Yazedjian et al., 2007). Memiliki minat yang sama dengan teman di perguruan tinggi berkorelasi juga dengan perkembangan diri yang lebih baik dan membuat mahasiswa memiliki ikatan yang lebih kuat dengan kampus (Swenson Goguen et al., 2010).

Berdasarkan data diskriptif subjek penelitian, mahasiswa yang menjadi responden penelitian ini adalah mahasiswa semester satu dan tiga atau mahasiswa tahun pertama dan kedua. Sebagaimana menurut Yazedjian et al., (2007) mahasiswa yang memiliki teman dan terlibat dalam kegiatan bersama lebih cenderung bertahan di tahun kedua kuliah. Ini terbukti dari data akademik mahasiswa non aktif pada angkatan 2020 yang memiliki 10\% mahasiswa non aktif, lebih kecil prosentasenya dibandingkan mahasiswa tahun ketiga yang mencapai 19\% mahasiswa non aktif. Hasil analisa diskriptif diketahui ketekunan akademik mahasiswa berada dalam kategori sedang, mengindikasikan bahwa mahasiswa memiliki tujuan yang cukup baik dalam hal akademik, baik tujuan jangka pendek maupun jangka panjang. Tujuan jangka pendek mencakup upaya-upaya saat ini dalam mengikuti kegiatan akademik dengan baik, dan dapat menghindari kebosanan, sedangkan tujuan jangka panjang mencakup upaya untuk terus berkomitmen mengembangkan diri meskipun mengalami hambatan.

Bantuan dan dukungan dari teman-teman kelompok yang didapatkan oleh mahasiswa membuat mahasiswa lebih mudah menyesuaikan diri pada tahun-tahun awal menempuh perkuliahan di perguruan tinggi karena kemampuan mahasiswa dalam penyesuaian sosial memainkan peran penting dalam ketekunan di perguruan tinggi (Gray et al., 2013). Hal ini memungkinkan mahasiswa untuk tetap lebih fokus dan berdedikasi pada studi mereka sehingga menghasilkan kinerja akademik yang lebih baik. Adanya perhatian, kepedulian, kepercayaan, akan membuat mahasiswa baru menemukan kenyamanan dalam memiliki teman baru yang dirasa senasib. Kenyamanan ini menghasilkan ketekunan dari tahun pertama hingga tahun kedua di perguruan tinggi (Swenson et al., 2008). Dapat difahami jika mahasiswa yang kurang terlibat secara sosial berpotensi akan mengalami putus sekolah (drop out) (Roland et al., 2016). Berdasarkan uraian di atas, dapat disimpulkan bahwa dengan adanya dukungan sosial kelompok atau teman belajar, menjadikan mahasiswa merasa dirinya penting dan berarti bagi kelompok, hal ini dapat mengarah pada hal yang positif yakni meningkatnya ketekunan akademik, yang pada akhirnya membantu mahasiswa mencapai tujuan akademik mereka.

\section{KESIMPULAN}

Dukungan sosial komunitas belajar berkorelasi positif dengan ketekunan akademik pada mahasiswa, semakin tinggi dukungan yang diterima oleh mahasiswa akan semakin meningkatkan ketekunan akademik. Implikasi dari penelitian ini, agar mahasiswa memiliki 
kelompok belajar yang dapat memberi support akademik maupun non akademik. Untuk institusi agar memperkuat program pendampingan dan sistem pendukung dalam bentuk fasilitas bimbingan akademik maupun bantuan-bantuan lain yang akan meningkatkan ketekunan akademis mahasiswa.

\section{DAFTAR PUSTAKA}

Bagian Administrasi Akademik (BAA). (2021). Laporan data mahasiswa aktif-non aktif. Baker, L. L. (2017). What It Takes to Succeed: The Importance of Social Support for Academically Successful Middle School English Learners. Youth and Society, 49(5), 658-678. https://doi.org/10.1177/0044118X14553581

Cohen, S. (2004). Cohen (2004) - Social Relationships and Health. American Psychologist, November, 676-684.

Furrer, C., \& Skinner, E. (2003). Sense of relatedness as a factor in children's academic engagement and performance. Journal of Educational Psychology, 95(1), 148-162. https://doi.org/10.1037/0022-0663.95.1.148

Gloria, A. M., \& Ho, T. A. (2003). Environmental, social, and psychological experiences of asian american undergraduates: Examining issues of academic persistence. Journal of Counseling and Development, 81(1), 93-105. https://doi.org/10.1002/j.15566678.2003.tb00230.x

Grant, N., Hamer, M., \& Steptoe, A. (2009). Social isolation and stress-related cardiovascular, lipid, and cortisol responses. Annals of Behavioral Medicine, 37(1), 29-37. https://doi.org/10.1007/s12160-009-9081-z

Gray, R., Vitak, J., Easton, E. W., \& Ellison, N. B. (2013). Examining social adjustment to college in the age of social media: Factors influencing successful transitions and persistence. Computers and Education, 67, 193-207. https://doi.org/10.1016/j.compedu.2013.02.021

Lotkowski, V. a, Robbins, S. B., \& Noeth, R. J. (2004). The Role of Academic and NonAcademic Factors in Improving College Retention. Office, September 12, 2007, 1-31.

Muwonge, C. M., Schiefele, U., Ssenyonga, J., \& Kibedi, H. (2017). Determinants of persistence among science teacher-trainees: Examining the role of self-efficacy, task value, and academic hope. Journal of Science Teacher Education, 28(6), 522-548. https://doi.org/10.1080/1046560X.2017.1379860

Nicpon, M. F., Huser, L., Blanks, E. H., Sollenberger, S., Befort, C., \& Kurpius, S. E. R. (2006). The relationship of loneliness and social support with college freshmen's academic performance and persistence. Journal of College Student Retention: Research, Theory and Practice, 8(3), 345-358. https://doi.org/10.2190/A465-356M-7652-783R

Roland, N., Frenay, M., \& Boudrenghien, G. (2016). Towards a Better Understanding of Academic Persistence among Fresh-men: A Qualitative Approach. Journal of Education and Training Studies, 4(12). https://doi.org/10.11114/jets.v4i12.1904

Sarafino, E. P., \& Smith, T. W. (2014). Health psychology: biopsychosocial interactions (Eighth). Wiley.

Shiddiq, M. I., Fitra, M. A., Patricia, R., Afriani, D. I., Bahar, F. A., \& Malay, E. D. (2020). Social Support is Positively Correlated With College Adjustment in First-Year Students. 494(Iciap 2019), 549-558. https://doi.org/10.2991/assehr.k.201125.046

Skahill, M. P. (2002). The Role of Social Support Network in College Persistence among Freshman Students. Journal of College Student Retention: Research, Theory \& Practice, 4(1), 39-52. https://doi.org/10.2190/lb7c-9ayv-9r84-q2q5 
Swenson Goguen, L. M., Hiester, M. A., \& Nordstrom, A. H. (2010). Associations among peer relationships, academic achievement, and persistence in college. Journal of College Student Retention: Research, Theory and Practice, 12(3), 319-337. https://doi.org/10.2190/CS.12.3.d

Swenson, L. M., Nordstrom, A., \& Hiester, M. (2008). The role of peer relationships in adjustment to college. Journal of College Student Development, 49(6), 551-567. https://doi.org/10.1353/csd.0.0038

Thalib, T., Hanafi, S., \& Irbah, S. (2018). The Academic Persistence Scale. Science And Education For Improving Learning Quality In Moluccas Archipelago, May 2019, 122 130.

Yahya, M., \& Bahri, S. (2016). Identifikasi Masalah-masalah yang dialami mahasiswa fakultas teknik dan ekonomi UNSYIAH. Jurnal Bimbingan Konseling FKIP UNSYIAH, 1(1), 3739.

Yazedjian, A., Purswell, K., Sevin, T., \& Toews, M. (2007). Adjusting to the First Year of College: Students' Perceptions of the Importance of Parental, Peer, and Institutional Support. Journal of the First-Year Experience \& Students in Transition, 19(2), 29-46. 